\title{
ROLE OF SOCIAL MEDIA IN BRAND DEVELOPMENT
} IN SAUDI ARABIA

\author{
ABEER ABDULLAH AL SAUD, MUHAMMAD RAHATULLAH KHAN
}

Effat University, Jeddah, Saudi Arabia

\begin{abstract}
Literature is ripe with the scholarly contributions on brand development from all aspects. The new marketing tools and techniques are introduced frequently. However, the impact social media has had on brand development is no match to traditional promotion in 4Ps. The information about Saudi Arabia is specially rare. This article based on a survey of 200 social media users on www.surveymonkey.com evaluates the role of social media in brand development in Saudi Arabia. The results from this Saudi example show that social media including Facebook and Twitter are among the most effective tool to develop a brand as compared to traditional promotional methods. It has also been found that these media are more successful in Saudi Arabia to develop the brand recall and image.
\end{abstract}

\section{JEL CLASSIFICATION \& KEYWORDS}

- M31 - M37 - M39 - SOCIAL MEDIA — BRAND DEVELOPMENT - SAUDI ARABIA

\section{INTRODUCTION}

This paper explores the role of social media in Saudi Arabia in brand development based on a quantitative survey developed and then carried out online at www.surveymonkey.com. More details are provided in the section on methodology. The survey was responded by 200 users of social media.

Marketers all over should learn to adapt to these changes because marketing is not as easy as it used to be since today's consumer is well informed and can easily compare products with one another (Kotler, Kartajaya and Setiawan, 2010). On the other hand brands that play vital role in business growth these days are defined by Clow and Baack (2009:58) saying that 'Brands are names assigned to an individual good or service or to a group complementary products'. Whereas, Kotler and Armstrong (2007:232) suggest that 'A brand is the company's promise to deliver a specific set of features, benefits, services and experiences consistently to the buyers'. They all agreed that brand is what distinguishes the company or product apart from competitors. Solomon, 2009:248 suggests that it has to have a strong presence and stand out amongst the thousands of brands that consumers are exposed to every day. 'A successful brand personality often is key to build brand loyalty'. Customers need to relate to a brand in order for them to favor it over the others. 'A brand is not what a company says it is; it is what customers say it is' (Yin, Holland, Qin and Wu, 2007:60-68). Kotler and Armstrong (2007) also motioned that having a good brand name adds to success of the brand and 'successful brands, engage customers on a deep emotional level'. How consumers see brands is strongly linked with their experience, therefore delivering a supreme brand experience is becoming essential (Cliffe and Motion, 2004).

Over the past two decades the world has gone through a major transformation and that is evident in all aspects of our life. That is due to the advancements in technology. We saw changes in our lifestyle, education, social norms and behaviors. People do not like to be told what to do and what to buy, they want to make that decision themselves and seek the needed information from each other. The introduction of www.journals.cz/ social media has just empowered their new way of thinking and marketers need to be aware of these changes that are happening so fast. According to Macy and Thompson (2011) "In an era when information travels at phenomenal speed along the "real time Web", a brand can explode into popular culture overnight and die just as quickly. As a marketer, how can one stay ahead of the curve? How do we control the chaos? Two words: Social Media'.

So, what does "Social Media" mean? First, 'Social, refers to the instinctual needs humans have to connect with other humans' and 'Media used with which people make those connections with others' (Safko, 2010:4). Social Media includes everything from MySpace and Facbook to business networking sites, Podcasts and collaborative sites such as Wikipedia. Why is it important? And why should marketers pay attention to it? Because according to Briones, Kuch, Liu and Jind (2010) two thirds of the world's Internet users have visited a social networking or a blogging site. People are coming together and forming groups according to their interests. Carlson, Suter and Brown (2007) call these groups 'social brand communities', people who may never interact directly with each other but still communicate through virtual online communities and so forth.

There is also a group called a 'psychological brand community'. This group consists of brand followers who feel a sense of connection with other people who share the same interests, but this group does not interact with each other in any way. These formations are giving consumers more and more power. Berthon, Pitt, McCarthy and Kates (2006) suggest that consumers are not inactive receivers anymore and that they are now more active helping companies with new product design and endorsements. Hanna, Rohm and Crittenden (2011) think that Social Media has 'fundamentally altered marketing's ecosystem'. To them, the change in the business world goes along with the advancements in technology and that it is now defined by customer 'connectivity' and 'interactivity'.

In order for their efforts to succeed, marketers are trying out several media networks at a time. They also believe that marketing cannot be just about getting attention via reach only; they should also focus on capturing and continuing attention through engagement. Because to them, consumers want to have a hand in the media process, and in order to provide that: 'Companies should view their approach to social media as an integrated strategy that brings consumer experiences to the forefront, all whilst recognizing that Internet based media does not replace traditional media'. They also took Corcoran's (2009) division of the marketing ecosystem which includes:

- Owned Media (Under the control of the marketer),

- Paid Media (Purchased by the marketer),

- Earned Media (i.e. word of Mouth).

Hanna, Rohm and Crittenden also think that it is essential for any business to know how to control and maneuver around these factors. On the other hand, Founier and Avery (2011) are not big fans of brands entering the 'realm' that is called Social Media. They say 'Brands today claim hundreds of thousands of face book friends, Twitter followers, online 
community members, and YouTube fans; yet, it is a lonely scary time to be a brand manager'. To them, the Web was created to connect people together and not for companies to sell brands. Founier and Avery do not deny that these networks gave marketers more information such as consumer preference, better targeting, more personalized messages and stronger relationships with them. On the other hand, they state that consumers think of these networks as their 'own space', therefore brand directors lost their control and consumers started resenting and avoiding ads. They state that 'Consumers were using social media to target brands and companies rather than brands using social media to target them'.

\section{Saudi Arabia}

Al Farsy 1980 argues that Saudi Arabia is not only a religious state it possesses strategic location and huge oil and gas reserves. However, studies of Field in 2000 and Auty in 2001 provide a striking view of the Kingdom and provided the details of economic transformation taken place over last 3 decades. They showed that the magnitude and the speed of the socio-economic transformation and facing and quelling the challenges that accompanied such swift conversion enabled Saudi Arabia achieve fascinating development. Saudi Arabia has 26 per cent of the world's total oil reserves Auty, 2001; Field, 2000). Studies also argue that the kingdom has challenges in growth and development and use of It resources.

The above discussion shows that there is a body of scholars who advocate for a new way of marketing through social media. They argue that there is a noticeable impact on brand development, growth and its recall when social media comes in play. Social media they suggest helps brand grow across boundaries.

This paper digs deeper in how social media affects branding in Saudi Arabia. How brands are developed through social media in the Kingdom? We ask the following questions.

1. How are brands developed in Saudi Arabia particularly?

2. Whether marketers in the Kingdom have no control on brand development anymore in the country?

3. Is it the company or the consumer who controls the brand?

4. Can brands be developed successfully through Social Media?

\section{Methodology}

The literature suggests that questionnaires offer rating scales with only the end points labeled with words and the points in between either represented graphically or labeled with numbers and not words (Krosnick and Berent 1993).

A questionnaire was developed and it was decided to conduct the survey online using any of the survey websites. It was found that the www.surveymonkey.com is more comprehensive, provides more detailed information and the results can be exported for advanced statistics. Website also specializes in the carrying out the survey for diverse fields and specialties. The survey was conducted for a period of 21 days from November 10 to 30,2012 . The survey announcement was made on the social media including face book, LinkedIn and Fainak (A Local Saudi networking site).

In the study, in order to improve reliability and validity points on the scale were provided with clear guidelines and labels, to clarify the meanings of the scale points as suggested by the literature. Schwarz et al. (1985) postulate that on some rating dimensions, respondents fall in the middle of the scale, and some answerers are biased toward placing themselves near that point, regardless of the labels used to define it. The numbers used by researchers to label rating-scale points can have unanticipated effects, though such numbers can be selected arbitrarily. Following from this an 11-point scale was provided of $0-10$, with clear guidelines.

The cognitive process literature, such as Tourangeau and Rasinski (1988); and Krosnick \& Fabrigar (1998) suggest that there is a complex four-step procedure involved through which a respondent undergoes before answering a question. The researchers attempted to design the questionnaires in a manner that the responses could be, optimized and answerers are driven to avoid biases mentioned above and provides the optimal answer. Each of these steps involved a great deal of thought for example, as the question interpretation can be, decomposed into four cognitive steps again, which in turn is guided by a complex and extensive, set of rules. The questions regarding the main measures were carefully written, and checked and verified during pilot study.

As there is a lack of information on Saudi Arabia and more specifically in the field of study therefore, it was decided to adopt a mix of quantitative and qualitative research was used as according to Burns and Bush (2010) quantitative research consists of prearranged questions in which the answers are set and a number of respondents are involved. On the other hand qualitative research involves gathering, evaluating and interpreting data through the observation of individuals' actions and sayings.

A varied approach was adopted in designing the questionnaire and included some closed ended questions, but such questions were limited to information that is actually straightforward. The study focuses on the Saudi Arabia therefore focus was on getting the input of different people who vary in behavioral, demographic and psychographic attributes.

Due to time constraints and limited resources, it was decided to adopt "convenience and referral sampling". Therefore, we

1. Conducted an online survey of 200 individuals.

2. Validation interview from a business owner that developed its brand through Social Media in Saudi Arabia.

\section{Limitations}

Like any other research, there were challenges faced in this work as well which included the following:

- Lack of Cooperation: As the research culture is developing in the kingdom, securing cooperation is a major hurdle. Some people resisted filling out the survey and others skipped some of the questions I needed them to answer.

- Lack of Data: Not enough studies or information with regards to the topic and Saudi Arabia.

- The domain of research is comparatively new. Hence little information available.

\section{Survey}

The survey was conducted for a period of 21 days from November 10 to 30,2012 and 200 social media users responded

Demographics

The respondents' demographics (table 1) show a mix of genders, educational level and current status. In all 45 males and 155 females responded. Major age group being 18 to 35 years old with 88 people holding bachelors and 60 with masters degree. Out of these 58 are students, 59 are working and 41 are house wives. The respondents also 


\begin{tabular}{|c|c|c|c|c|c|c|c|c|c|c|c|c|c|}
\hline \multicolumn{14}{|c|}{ Demographics } \\
\hline Age & \multicolumn{2}{|c|}{ Gender } & \multirow[t]{2}{*}{ Total Nos } & \multicolumn{6}{|c|}{ Education } & \multicolumn{4}{|c|}{ Status } \\
\hline & Male & Female & & None & Secondary & Graduate & Masters & Doctoral & Others & Student & Working & House wife & Unemployed \\
\hline $18-23$ & 14 & 59 & 73 & & 12 & 61 & & & & 37 & 13 & 17 & 6 \\
\hline $24-29$ & 8 & 47 & 55 & & & 14 & 41 & & & 13 & 28 & 14 & \\
\hline $30-35$ & 17 & 19 & 36 & & & 13 & 19 & 4 & & 8 & 18 & 10 & \\
\hline $41-45$ & 2 & 9 & 11 & & & & 8 & 3 & & & 10 & 1 & \\
\hline Above 45 & & 4 & 4 & & & & 4 & & & & 2 & 2 & \\
\hline
\end{tabular}

included 7 post master's degree holders. These shows the generation of consumers who want to be trend setters rather than followers in new look Saudi Arabia. They are also brand conscious and truly care about what they purchase.

\section{Discussion}

In this section each of the question in survey is identified and its answer briefly discussed.

\section{Brand awareness}

A list of brands from different sectors was provided and respondents had to identify if they know the brands and or purchase all of them; the brands included:

Zara, Nike, Channel, D\&G, Apple, Microsoft , Mc Donalds, Al Baik, Coca-Cola, 7Up, Pepsi, STC, Mobily, Vodaphone, Kellogg's, Kodak, Canon, Nikon, British Airways, Saudi Airlines, Emirate Airlines, Audi, Mercedes, BMW, Porsche, Toyota, Honda, Panda, Laylati, Danube, Nissan, M\&S, Debenhams, Ford, L'Oreal, Hilton, Holiday Inn, Clarks, Sony, Hitachi, Philips, Dell, Toshiba, Moulinex, Black and Decker, Black berry, Nokia, Sony Ericson, TGI Fridays, McDonalds, Munch, Toki, Tao, Roma, Applebee's etc.

The survey results showed that only $8.88 \%$ of the respondents knew about and used all of the brands stated above and the rest were familiar and have tried out some of the brands. It was asked deliberately that whether the people know and use all these brands, because these brands in Saudi Arabia are popular and are selected from different business sectors. This also showed that the people may be aware of these brands but are not using all the brands which implies that there is some distance to cover to become completely brand oriented society.

\section{Taking notice of a brand}

The table 2 provides an interesting finding which shows that though majority of Saudi consumers rely on recommendations when making a purchase and that traditional media is still a big part of consumers' lives. However, the role of the social networks is starting to catch up to the conventional promotional methods. In a comparatively very short time social media has picked up and race with traditional promotional methods.

\section{Use of promotional media by brands}

The response as shown in figure 1 confirms our earlier contention that the social media is picking up and the

\begin{tabular}{|l|l|}
\hline Table 2: Taking notice of the brand \\
\hline Answer Options & Response Percent \\
\hline Word of Mouth (From Family, friends...) & $94,6 \%$ \\
\hline Advertisements (TV, Radio...) & $74,3 \%$ \\
\hline Internet & $41,9 \%$ \\
\hline $\begin{array}{l}\text { Social Networks (Facebook, Twitter, } \\
\text { Fainak }\end{array}$ & $33,8 \%$ \\
\hline Other & $14,9 \%$ \\
\hline Source: Surveymonkey.com survey response summary \\
\hline
\end{tabular}

traditional media may face a stiff competition soon. The internet and different social networks are competing against the traditional media (print, TV and radio).

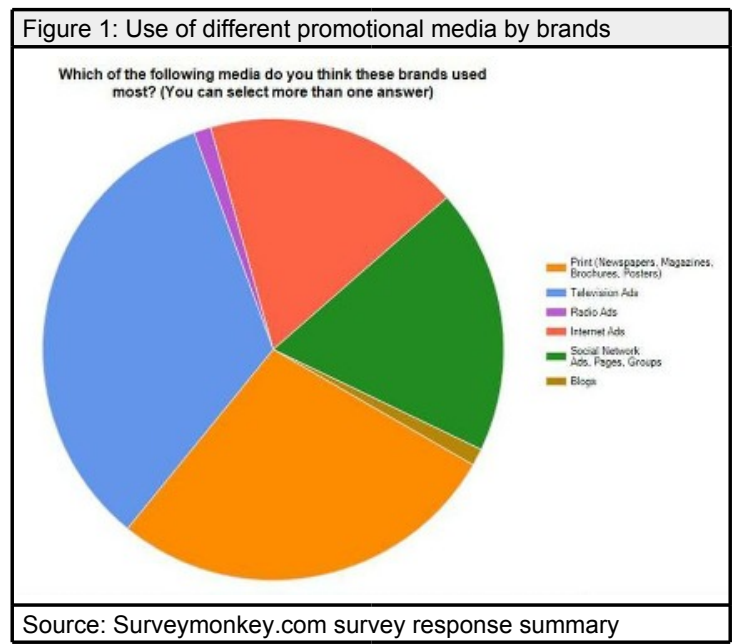

\section{The role of Social Media}

A looped question was posed in order to know if the brands should use more social media to keep contact (explained as promotion and contact both in the question). The people with the 'yes' or 'no' answer had to then justify their option. The findings are that consumers overwhelmingly understand the importance and benefit of social media for the businesses. In all $75.7 \%$ of the respondents think that brands should be on the social media.

In order to understand why respondents considered these websites important in marketing, three options were provided, i.e.

1. Social Media sites are becoming important for marketing.

2. More and more people are subscribing to these sites.

3. Social media sites provide large potential market base.

Responses tabulated in table 3 reveal customers are geared towards marketability through these sites and answerers suggested that social media sites are important for marketing and development of brands.

\begin{tabular}{|l|l|}
\hline Table 3: Role of Social Media \\
\hline Answer Options & Response Percent \\
\hline Yes & $75,7 \%$ \\
\hline No & $12,2 \%$ \\
\hline Don't know & $12,2 \%$ \\
\hline Source: Surveymonkey.com survey response summary \\
\hline
\end{tabular}

\section{Decision making change through Social Media promotions}

In order to know is whether people have noticed a change in their buying behavior ever since social networks came 
into existence. A great majority (60.6\%) of the respondents answered that yes the social media campaigns did alter their decision making to purchase a brand.

\section{Use of Social Media to gain more information about a brand}

The power of social media is evident here. It has only been around for a few years and more than half of the respondents in Saudi Arabia use it as a reference when making a purchasing decision.

\begin{tabular}{|l|l|}
\hline Table 4: Use of Social Media \\
\hline Answer Options & Response Percent \\
\hline Yes & $52,2 \%$ \\
\hline No & $47,8 \%$ \\
\hline Source: Surveymonkey.com survey response summary \\
\hline
\end{tabular}

Respondents were then asked to provide reasons behind their online search through social networks. It was an open ended question and respondents could opt for more than one answer. The answers shown in table 4 and figure 2 are based on number of times the option has been selected. It shows that the restaurant search, foreign destinations, brands and products not available in Saudi Arabia are major reasons for logging to the social media.

\section{Saudi Brands on Social Media}

Social media including Twitter, Face book and Fainak (a local social networking site) were searched before the survey design and it was found that a number of brands including "What's up Jeddah" (Magazine), "Mobily" (Telecommunications company), "Sotra" (Fashion designer), "Munch" (Bakery) and "Tao" (lounge / restaurant) have presence on social media.

The majority of respondents recognized the Saudi brand presence on the social media. It also implies that the Saudi users not only use the social media but are aware of the native brands as well.

\section{Use of Social Media by local brands}

This question was aimed at knowing which of the social media website is mostly used. The overwhelming answer detailed in figure 3 shows that Face book is used by more than $65 \%$ of the respondents. The local Saudi social media site "Fainak" is used by $12 \%$ of the respondents.

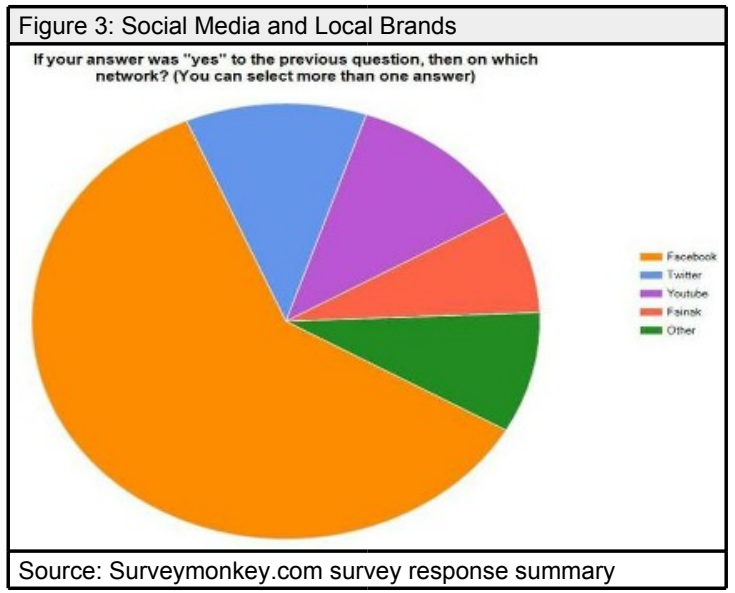

\section{Future role of Social Media in Saudi Arabia}

The respondents seemed quite confident about the future role of social media in promotion of the brands in Saudi Arabia and more than $92 \%$ answers were in affirmative

\section{Effect on Social Media on Brand}

The graph in figure 4 shows that the majority of respondents believe that social media can play role in brand recall and brand image development. On the other hand the opinion regarding development of brand loyalty is divided almost equally. This is quite understandable that the media will not develop the loyalty but the experience of the brand will do that.

\section{Conclusion}

The above findings reveal that having a good brand image, recall and loyalty is essential for an organization to prosper and grow. Consumers need to have a sense of belonging; they also need to feel appreciated. A strong brand can help businesses lead the market, target the right consumer and convey the correct image. Building a strong brand that has clear characteristics will help companies satisfy that need and social media will help them get their message out there and reach the right people.

It can also be implied and concluded that social media is just as powerful in Saudi Arabia as it may be in other parts

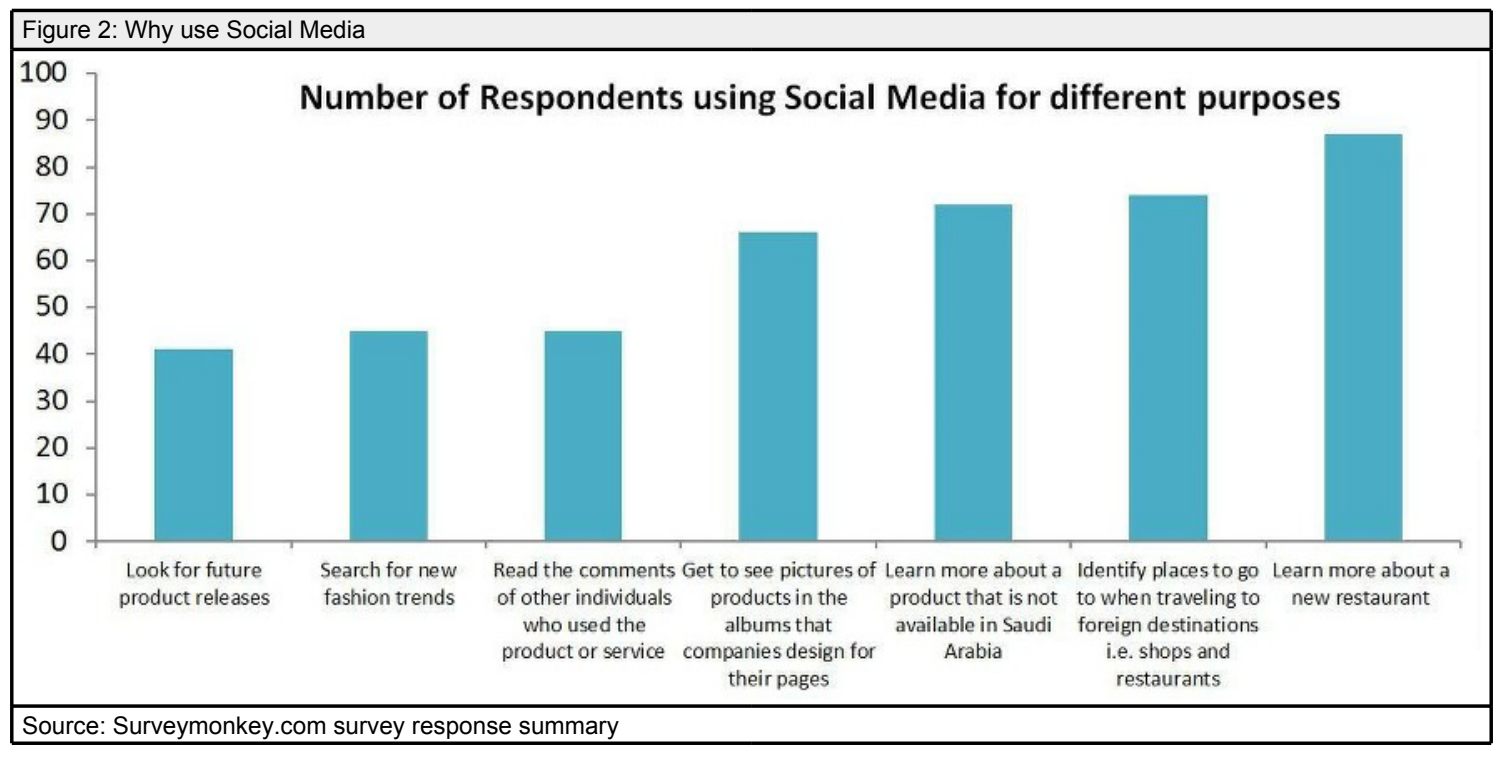




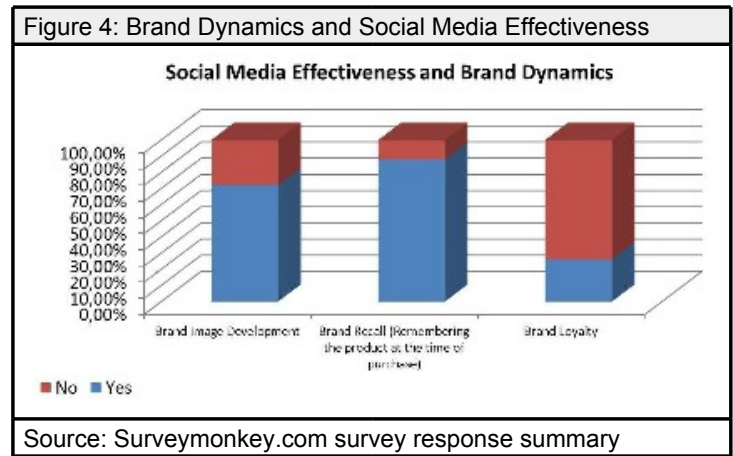

of the world. It has the same benefits and limitations. Local consumers are abreast of developments and rely on these websites. Consumers also see it as a safe-haven where they can interact with one another.

It also entails that there is a need for the brand oriented businesses to provide a presence on the social networks in Saudi Arabia. As we live in fast paced world; social media has just made it faster. We have seen the changes it has made in only five years which traditional media took decades to create.

The result of this survey reinforces the idea that a new generation of consumers are taking over the market place. These people are alert, knowledgeable and powerful. They have altered the business world's ecosystem and are gaining more control.

\section{REFERENCES}

1. Al-Farsy, F. (1980). Saudi Arabia; A Case Study in Development (2nd ed.). Stacey International, London.

2. Auty, R.M. (2001). A growth collapse with high rent point resources: Saudi Arabia, in Auty, R.M. (Ed.). Recourse Abundance and Economic Development. pp. 193-207. Oxford University Press, New York, NY.

3. Berthon, R., Pitt, F., McCarthy, I. and Kates, S. (2006). When Customers Get Clever: Managerial Approaches to Dealing with Clever Customer. Business Horizon, Vol.50, pp.39-48. http://dx.doi.org/10.1016/j.bushor.2006.05.005

4. Briones, R., Kuch, B., Liu, B., and Jin, Y. (2010). Keeping Up With The Digital Age: How the American Red Cross Uses Social Media to Build Relationships. Public Relations Review, Vol.37, pp.37-43. http://dx.doi.org/10.1016/j.pubrev.2010.12.006

5. Carlson, B., Suter, T. and Brown, T. (2007). Social Versus Psychological Brand Community: The Role of Psychological Sense of Brand Community. Journal of Business Research, Vol.61, pp.284291. http://dx.doi.org/10.1016/j.jbusres.2007.06.022

6. Cliffe, S. and Motion, J. (2004). Building Contemporary Brands: a sponsorship based strategy, Journal of Business Research. Vol.58, pp.1068-1077. http://dx.doi.org/10.1016/j.jbusres.2004.03.004

7. Clow, K. and Baack, D. (2009). Integrated Advertising, Promotion, and Marketing Communications, 4th edition, Global Edition: Pearson.

8. Corcoran, S. (2009). Defining Owned, Earned and Paid Media. Retrieved from: http://blogs.forrester.com/interactive_marketing/2009/12/definingearned-owned-and-paid-media.html [Äccessed on 6-4-2011].

9. Field, M. (2000). The Arabian Gulf: the good times have gone. Euromoney, No. 378, pp. 123-6.

10. Fournier, S. and Avery, Jill. (2011). The Uninvited Brand. Kelley School of Business. USA

11. Hannah, R., Rohm, A. and Crittenden, V. (2011). We're All Connected: The Power of the Social Ecosystem. Kelley School of Business.USA
12. Hooley, G., Piercy, N. and Nicoulaud, B. (2008). Marketing Strategy and Competitive Positioning (4th ed.). Edinburgh: Pearson, Prentice Hall.

13. Kotler, P., Katarjaya, H. and Setiawan, I. (2010). Marketing 3.0. New Jersey: John Wiley and Sons. http://dx.doi.org/10.1002/9781118257883

14. Kotler, P. and Armstrong, G. (2008). Principles of Marketing, 12th edition, New Jersey: Pearson, Prentice Hall.

15. Macy, B. and Thompson, T. (2010). Power of Real-Time Social Media Marketing, USA: McGraw Hill.

16. Ries, A. and Ries, L. (2002). The 22 immutable laws of Branding. HarperCollins Publishers.

17. Safko, L. (2010). The Social Media Bible: Tactics, Tools, and Strategies for Business Success (2nd ed.). New Jersey: John Wiley \& Sons, Inc.

18. Solomon, M. (2011). Consumer Behavior: Buying, Having, and Being (9th ed.). New Jersey: Pearson, Prentice Hall.

19. Yin, Y., Holland, R., and Wu, W. (2007). Development of a Customer Experience-Based Brand Strategy for the Lenevo Group to Explore the UK Market. Design Management Journal, Vol.3, pp. 60-68. http://dx.doi.org/10.1111/j.1948-7177.2008.tb00008.x

Article DOI: http://dx.doi.org/10.12955/ejbe.v8i1.1 